\title{
Modeling the Photocatalytic Mineralization in Water of Commercial Formulation of Estrogens 17- $\beta$ Estradiol (E2) and Nomegestrol Acetate in Contraceptive Pills in a Solar Powered Compound Parabolic Collector
}

\section{José Colina-Márquez ${ }^{1, *}$, Fiderman Machuca-Martínez ${ }^{2, \dagger}$ and Gianluca Li Puma $^{3, \dagger}$}

1 Program of Chemical Engineering, Universidad de Cartagena Piedra de Bolívar Campus, Av. El Consulado 48-152, A.A. 130015, Cartagena de Indias, Colombia

2 School of Chemical Engineering, Universidad del Valle, Campus Meléndez, Calle 13 No. 100-00, A.A. 25360 Cali, Colombia; E-Mail: fiderman.machuca@correounivalle.edu.co

3 Environmental Nanocatalysis \& Photoreaction Engineering, Department of Chemical Engineering, Loughborough University, Loughborough LE11 3TU, UK; E-Mail: g.lipuma@lboro.ac.uk

$\dagger$ These authors contributed equally to this work.

* Author to whom correspondence should be addressed; E-Mail: jcolinam@unicartagena.edu.co; Tel.: +57-5675-2040 (ext. 117).

Academic Editor: Pierre Pichat

Received: 16 April 2015 / Accepted: 6 July 2015 / Published: 22 July 2015

\begin{abstract}
Endocrine disruptors in water are contaminants of emerging concern due to the potential risks they pose to the environment and to the aquatic ecosystems. In this study, a solar photocatalytic treatment process in a pilot-scale compound parabolic collector (CPC) was used to remove commercial estradiol formulations (17- $\beta$ estradiol and nomegestrol acetate) from water. Photolysis alone degraded up to $50 \%$ of estradiol and removed $11 \%$ of the total organic carbon (TOC). In contrast, solar photocatalysis degraded up to $57 \%$ of estrogens and the TOC removal was $31 \%$, with $0.6 \mathrm{~g} / \mathrm{L}$ of catalyst load $\left(\mathrm{TiO}_{2}\right.$ Aeroxide P-25) and 213.6 ppm of TOC as initial concentration of the commercial estradiols formulation. The adsorption of estrogens over the catalyst was insignificant and was modeled by the Langmuir isotherm. The TOC removal via photocatalysis in the photoreactor was modeled considering the reactor fluid-dynamics, the radiation field, the estrogens mass balance, and a modified Langmuir-Hinshelwood rate law, that was expressed in terms of the rate of photon adsorption. The optimum removal of the estrogens and TOC was achieved at a catalyst
\end{abstract}


concentration of $0.4 \mathrm{~g} / \mathrm{L}$ in $29 \mathrm{~mm}$ diameter tubular CPC reactors which approached the optimum catalyst concentration and optical thickness determined from the modeling of the absorption of solar radiation in the CPC, by the six-flux absorption-scattering model (SFM).

Keywords: emerging contaminants; pharmaceuticals; degradation; photoreactor design; six-flux model; UV-photolysis; Langmuir-Hinshelwood; modeling and simulation

\section{Introduction}

Pharmaceuticals and metabolites residues in the aquatic environment are cause of concern to many agencies, institutions and governments worldwide. Actions for monitoring their occurrence, preventive measures and novel technologies for their containment are currently being evaluated at national and international level [1-6]. Among many pharmaceuticals, endocrine disruptors in water are contaminants of emerging concern due to the risk they pose to the aquatic ecosystems and to the environment. Compounds with estrogenic, progestagenic and/or androgenic activities can have significant effect on humans and wildlife [7-10]. For example, the disruptive impact of 17- $\alpha$ ethynylestradiol (EE2) to the fish population in an experimental lake was demonstrated in a seven-year study, which showed near extinction of fish after four years of EE2 dosing, due to reproductive failure [11]. The female contraceptive pill active compounds $17-\beta$ estradiol (E2) and nomegestrol have recently been formulated as an alternative to pills containing the more common synthetic estrogen EE2, since these hormones are structurally identical to endogenous estrogen in women [12].

Current municipal wastewater treatment plants are unable to completely remove or destroy pharmaceuticals from domestic wastewater $[13,14]$. Advanced oxidation processes (AOPs), which are based on the generation of highly powerful reactive oxidative species (e.g., hydroxyl radicals), have been proposed as alternative processes to inactivate the biological and physiological effect of pharmaceuticals in water. Among AOPs, photocatalytic oxidation over an irradiated semiconductor photocatalyst (often titanium dioxide $\left(\mathrm{TiO}_{2}\right)$ ) has proven to be effective in the removal of pharmaceuticals including estrogens [15-18]. Most studies that investigate the photocatalytic degradation of estrogens deal with idealized systems, using ultrapure water, synthetic chemicals and laboratory reactors [19-24]. However, there is a little information on the effectiveness of photocatalysis for the destruction of commercial estrogens formulations at pilot-scale and using real water. These waters may be the effluents from pharmaceutical manufacturing processes.

In this study, we investigate the treatment of commercial estradiols (17- $\beta$ estradiol and nomegestrol acetate, Figure 1) aqueous solutions obtained from female contraceptive pills, in a pilot-scale compound parabolic collector (CPC) operated using a solar photocatalytic treatment process and titanium dioxide $\left(\mathrm{TiO}_{2}\right)$ suspensions. The radiation field in the CPC was modeled and the spatial distribution of the volumetric rate of photon absorption (VRPA) was evaluated by applying the six-flux photon absorption-scattering model (SFM) [25-27]. This model tracks scattered photons along the six directions of the Cartesian coordinates. The optical parameters of the catalyst suspension in water were averaged across the spectrum of the incident solar light to simplify the modeling methodology. The time-dependent degradation profiles of the commercial estrogens formulation in tap water were determined following 
the explicit consideration of the volumetric rate of photon absorption in the reaction kinetics and a mass balance across the CPC. The dependence of the treatment of the commercial formulation of estradiols on catalyst concentration and optical thickness was correlated to the rate of photon absorption in the reactor.

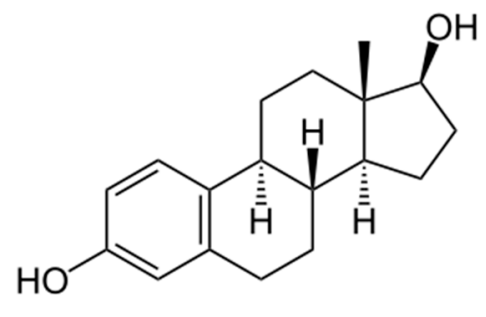

(a)

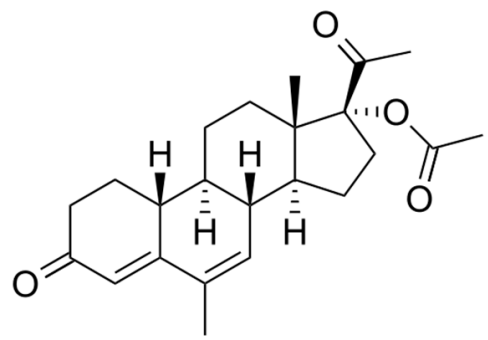

(b)

Figure 1. Chemical structures of the estrogens investigated: (a) 17- $\beta$ estradiol and (b) Nomegestrol acetate.

\section{Results and Discussion}

\subsection{Solar Photolysis}

Figure 2 shows the rate of degradation and mineralization of the commercial estrogen mixture in the CPC by solar photolysis, in the absence of catalyst. The estrogens concentration and TOC removal after $42 \mathrm{~min}$ of irradiation and at a photon irradiance of $30 \mathrm{~W} / \mathrm{m}^{2}$, was $49 \%$ and $11 \%$, respectively.

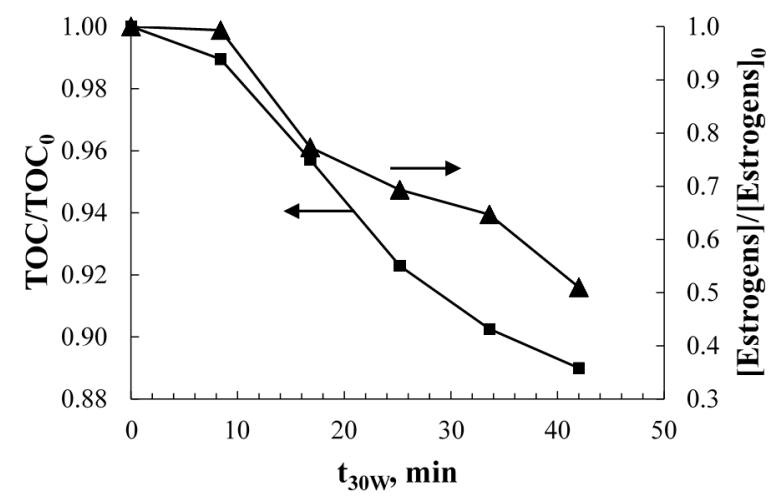

Figure 2. Solar photolytic degradation (right axis) and mineralization (left axis) of the commercial formulation of E2 and nomegestrol acetate mixture with an initial concentration of $5 \mathrm{ppm}$ of estrogens and $388 \mathrm{ppm}$ of TOC at $\mathrm{pH} 4.5$ and with $97.2 \mathrm{~kJ} / \mathrm{m}^{2}$ of accumulated solar radiation (measured as UV-A).

The observed behavior is similar to the rate of photolysis reported in previous studies [23]. The estrogen mixture shows significant degradation under UV radiation exposure, especially with UV-A and UV-C radiation [23]. Nonetheless, the TOC removal was not as fast as the removal of estrogens. This may result from the presence of excipients compounds in the commercial estradiols formulation, consisting of lactose monohydrate, microcrystalline cellulose, magnesium stearate and polyvinyl alcohol, which are not easily mineralized by UV photolysis. In addition, the transformation products by photolysis are expected to degrade at slower rates, since the aliphatic derivatives of the photolytic degradation of 
estrogens can be more stable than the aromatic rings under UV irradiation conditions [28]. Although solar radiation only contains a small proportion of UV-C, the collective contribution of the other UV components can be sufficient for breaking chemical bonds in the estrogens molecules [29]. The effect of solar photolysis is usually significant for the degradation of the estrogens parent compound in natural waters. However, in heterogeneous photocatalysis, the absorption of UV photons by the photocatalyst, in well designed reactors, is several orders of magnitude higher than the absorption of photons by the molecules in solution [23], therefore the effect of photolysis can often be neglected when the contaminants and TOC removals are modeled.

\subsection{Adsorption of Contaminants on the $\mathrm{TiO}_{2}$ Catalyst Surface}

The results of adsorption of the commercial estrogens mixture onto $\mathrm{TiO}_{2}$ are presented in Figure 3 in terms of residual estrogens and TOC concentrations. The catalyst loadings selected in this study were limited to those concentrations that maximized the rate of photon absorption in the CPC and that yielded

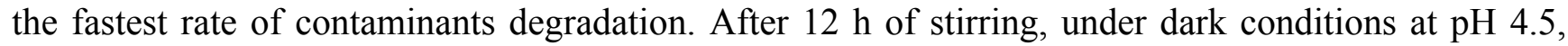
approximately $13.5 \%$ of the initial estrogens concentration was adsorbed onto the surface of $\mathrm{TiO}_{2}$. The role of adsorption can be significant in photocatalysis, since it can be rate-limiting to the contaminant degradation kinetics. The adsorption of hydroxyl anions onto the $\mathrm{TiO}_{2}$ surface promotes the generation of free hydroxyl radicals via electron exchange, which in turn oxidize water contaminants [30,31]. However, hydroxyl anions and the contaminant molecules compete for adsorption on the catalyst surface sites, therefore, if the fractional coverage of $\mathrm{OH}$ is lower than that of estrogens and drug additives, this might have an adverse effect on the rate of generation of oxidative species. Contrasting to this effect, if the adsorption of the chemical species of interest is weak, the observed photocatalytic degradation kinetics of the pollutant may be affected negatively and controlled by the rate of mass transfer of contaminants from the bulk to the catalyst surface.

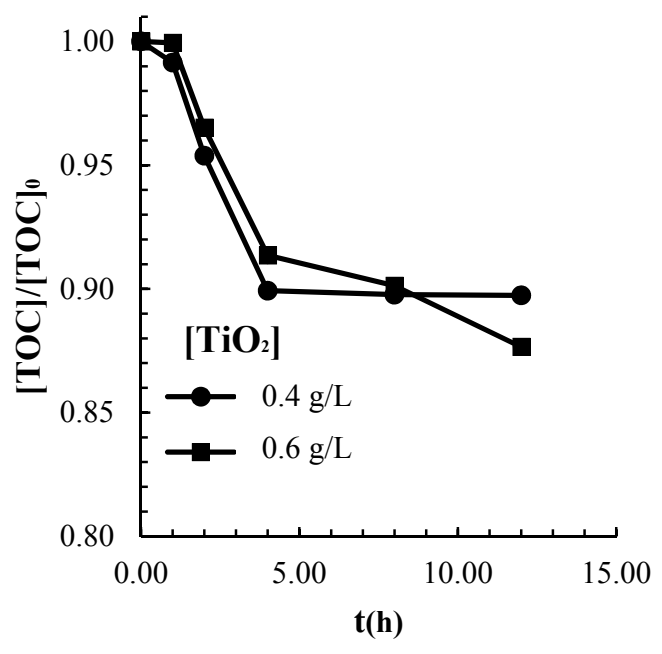

(a)

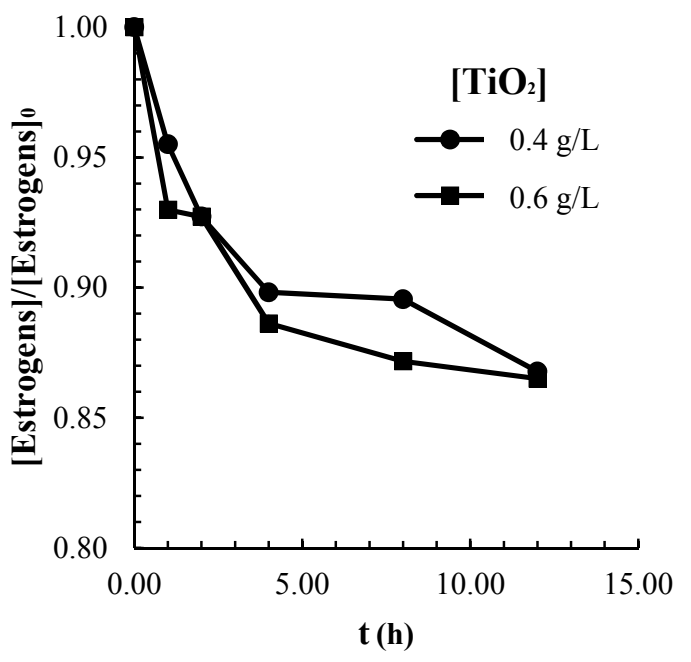

(b)

Figure 3. Adsorption of commercial estradiol at 0.4 and $0.6 \mathrm{~g} / \mathrm{L}$ of catalyst loading with an initial concentration of 7 ppm of estrogens and 429 ppm of TOC: (a) TOC removal and (b) Estrogens removal. 
The TOC of the estrogenic commercial drug was considered for modeling the adsorption phenomena onto the $\mathrm{TiO}_{2}$ photocatalyst. The observed adsorption of estrogens in terms of TOC removal shows a typical monolayer behavior, which can be described by a Langmuir isotherm, according to the adsorption equation:

$$
q=\frac{q_{0} K_{a d s}[T O C]}{1+K_{a d s}[T O C]}
$$

where $q$ is the amount of adsorbate per amount of adsorbent $\left(\mathrm{mg}_{(\mathrm{TOC})} / \mathrm{g} \mathrm{TiO}_{2}\right), q_{0}$ is the maximum amount of TOC adsorbed, [TOC] is the concentration of estrogens in solution $\left(\mathrm{mg}_{(\mathrm{TOC})} / \mathrm{L}\right)$ and $K_{a d s}$ is the adsorption equilibrium constant (L/mg (TOC)). After rearrangement Equation (1), can be written as a linear expression, Equation (2), which allows the estimation of the adsorption parameters by linear fitting of the TOC adsorption results (Figure 4).

$$
\frac{[T O C]}{q}=\frac{1}{q_{0} K_{a d s}}+\frac{1}{q_{0}}[T O C]
$$

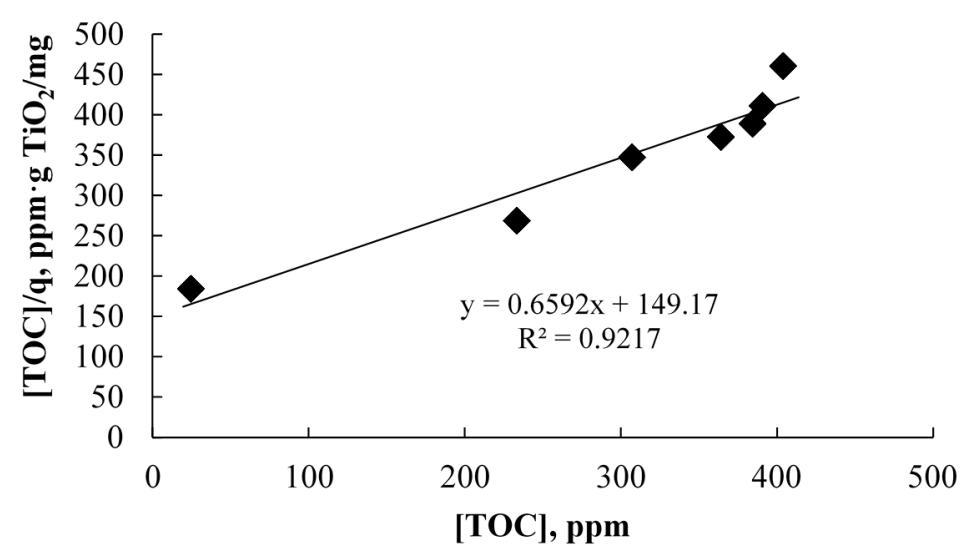

Figure 4. Linear regression of the Langmuir isotherm obtained from experiments at $30{ }^{\circ} \mathrm{C}$, pH 6.9 and with $0.6 \mathrm{~g} / \mathrm{L}$ of catalyst load.

The corresponding $q_{0}$ was $1.52 \mathrm{mg}(\mathrm{TOC}) / \mathrm{g} \mathrm{TiO}_{2}$, whereas $K_{a d s}$ was $4.42 \times 10^{-3} \mathrm{ppm}^{-1}$. The relatively small value of the equilibrium constant, $K_{a d s}$, suggest weak estrogens adsorption and pseudo first-order adsorption kinetics, as also shown in Figure 3. It is also possible that multilayer adsorption can be relevant at higher substrate concentrations above $400 \mathrm{ppm}$ TOC since the Langmuir isotherm appears to deviate from the experimental data.

\subsubsection{Photocatalytic Oxidation of a Commercial Formulation of Estrogens}

The experiments performed in the pilot scale photoreactor, in the presence of suspended $\mathrm{TiO}_{2}$, shows that the overall degradation rate of the commercial estrogens mixture increased as the initial concentration of the hormone disruptor decreased (Figure 5). 


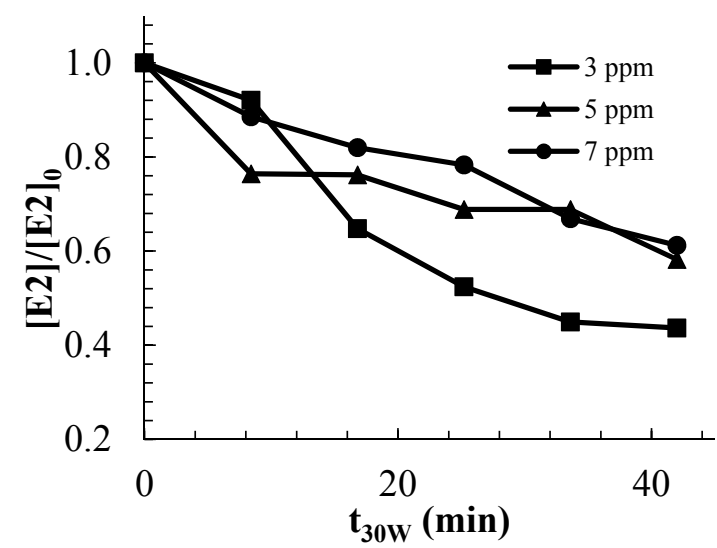

(a)

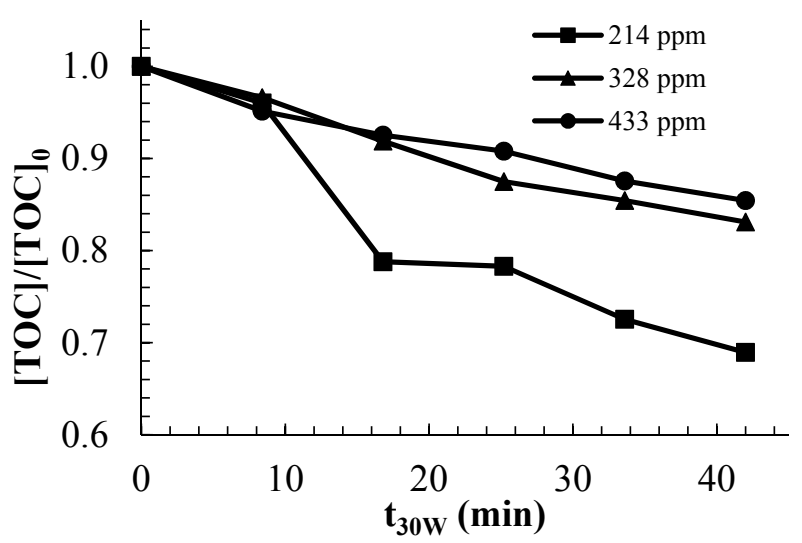

(b)

Figure 5. Effect of the initial concentration of the contaminant on the degradation rate with a catalyst load of $0.6 \mathrm{~g} / \mathrm{L}$; (a) Estrogens degradation; (b) TOC removal.

The estrogens removal was $56.7 \%, 41.7 \%$ and $38.7 \%$ for 3,5 and 7 ppm of initial estrogens concentration, respectively, which means that the removal rates $(\mathrm{ppm} / \mathrm{min})$ increased as the initial estrogen concentration increased, whereas the TOC removal was $31.1 \%, 16.9 \%$ and $14.6 \%$ for 214,328 and $433 \mathrm{ppm}$ of initial TOC concentration, respectively. This behavior is consistent with the prevalent trend observed in other studies involving the photocatalytic oxidation of contaminants in water [23,32-34]. In heterogeneous photocatalysis, the apparent contaminants oxidation rates can be limited by adsorption, therefore, the initial concentration of contaminants can have a significant effect on the observed degradation rate. According to the Langmuir kinetic model, lower initial concentrations lead to first-order rate law, whereas higher concentrations lead to zero-order rate law. Figure 5 shows faster removal of both estrogens and TOC at the lowest initial concentrations, which is consistent with a pseudo first-order behavior.

It should be observed that the rates of degradation of estrogens in the presence of $\mathrm{TiO}_{2}$ (Figure 5a) are not too dissimilar to the rate observed in the absence of catalyst (Figure 2), which contrast with other studies that have shown faster estrogens removal in the presence of $\mathrm{TiO}_{2}$ photocatalyst [23]. This apparent coincidence may erroneously suggest that photolysis alone may be the most important factor responsible for the degradation of the contaminants in the aqueous solutions. However, it should be observed that at the same time, the absorption of UV photons by the photocatalyst is several orders of magnitude higher than the absorption of photons by the molecules in solution [23], therefore, the effective photon irradiance available for the photolysis of the molecules in solution is also several orders of magnitude smaller in comparison to the case in which the photocatalyst is absent. Since the rate of contaminants photolysis is first-order on the photon irradiance (Beer-Lambert law), it can be concluded that the contribution of photolysis alone should be insignificant in the observed degradation and mineralization of the contaminants in the presence of a photocatalyst. This conclusion is further supported by the analysis of the transformation products of estrogens (EE2) observed under UVA photocatalysis, which show that oxidation of estrogens occurs by hydroxyl radical attack [19,35]. The mineralization results (Figure 5b) show faster TOC removal in the presence of $\mathrm{TiO}_{2}$ in comparison to photolysis alone (Figure 2). 
2.2.2. Modeling and Experimental Validation of the Solar Photocatalytic Degradation of Contraceptive Pills Formulations

Due to the complex nature of the commercial contraceptive pill formulation, the photocatalytic treatment process was followed and modeled in terms of TOC removal.

The modified Langmuir-Hinshelwood $(\mathrm{L}-\mathrm{H})$ rate model proposed by Li Puma et al. [27], was adopted to describe the photocatalytic degradation of the commercial estradiol mixture. The radiation field in the CPC was analyzed using the six-flux absorption scattering model (SFM) [26]. The set of equations are summarized as follows:

(1) Reactor mass balance (expressed as differential equation in polar coordinates):

$$
\frac{d[\text { TOC }]_{r, \theta}}{d t_{30 W}}=r_{T O C}
$$

(2) Contaminant rate law:

$$
r_{T O C}=-k_{T} \frac{K_{R}[T O C]}{1+K_{R}[T O C]} \int(L V R P A)^{m} d V_{R}
$$

(3) Mass balance in the batch recirculation system:

$$
[T O C]_{i+1}^{i n}=\frac{[T O C]_{i}^{i n}\left(V_{T}-V_{R}\right)+[T O C]_{i}^{o u t} V_{R}}{V_{T}}
$$

(4) Hydrodynamic model for turbulent flow in the CPC, which was operated in the turbulent flow regime:

$$
\begin{gathered}
\frac{v_{z}}{v_{z, \max }}=\left(1-\frac{r}{R}\right)^{\frac{1}{n}} \\
n=0.41 \sqrt{\frac{8}{f}} \\
v_{z, \text { average }}=\frac{Q}{\pi r^{2}} \\
\frac{v_{z, \text { max }}}{v_{z, \text { average }}}=\frac{(n+1)(2 n+1)}{2 n^{2}}
\end{gathered}
$$

(5) Optical properties of the catalyst and SFM parameters:

$$
\begin{gathered}
\omega=\frac{\sigma}{\sigma+\kappa} \\
a=1-\omega p_{f}-\frac{4 \omega^{2} p_{s}^{2}}{1-\omega p_{f}-\omega p_{b}-2 \omega p_{s}} \\
b=\omega p_{b}-\frac{4 \omega^{2} p_{s}^{2}}{1-\omega p_{f}-\omega p_{b}-2 \omega p_{s}} \\
\omega=(\sigma+\kappa) \delta C_{c a t}
\end{gathered}
$$




$$
\begin{gathered}
\tau_{a p p}=a \tau \sqrt{1-\omega_{c o r r}^{2}} \\
\gamma=\frac{1-\sqrt{1-\omega_{c o r r}^{2}}}{1+\sqrt{1-\omega_{c o r r}^{2}}} e^{-2 \tau} a p p \\
\lambda_{\omega_{c o r r}}=\frac{1}{a(\sigma+\kappa) C_{c a t} \sqrt{1-\omega_{c o r r}^{2}}}
\end{gathered}
$$

(6) The local volumetric rate of photon absorption (LVRPA) calculated from the SFM:

$$
\begin{gathered}
\text { LVRPA }=\frac{I_{0}}{\lambda_{\omega \operatorname{corr}} \omega_{\text {corr }}(1-\gamma)}\left[\left(\omega_{\text {corr }}-1+\sqrt{1-\omega_{\text {corr }}^{2}}\right) e^{-\frac{r_{p}}{\lambda_{\omega c o r r}}}\right. \\
\left.+\gamma\left(\omega_{\text {corr }}-1+\sqrt{1-\omega_{\text {corr }}^{2}}\right) e^{\frac{r_{p}}{\lambda_{\omega c o r r}}}\right]
\end{gathered}
$$

The parameters were fitted from the experimental results obtained with $0.6 \mathrm{~g} / \mathrm{L}$ of $\mathrm{TiO}_{2}$ using the optical properties of the Aeroxide P-25, shown in Table 1 [36].

Table 1. Optical parameters of $\mathrm{TiO}_{2}$ Aeroxide $\mathrm{P}-25$ in water averaged across the solar radiation spectrum up to the maximum wavelength that can photoactivate $\mathrm{TiO}_{2}(\lambda=385 \mathrm{~nm})$ [36].

\begin{tabular}{cc}
\hline Parameter & Value \\
\hline Absorption coefficient $(\kappa)$ & $174.7 \mathrm{~m}^{2} / \mathrm{kg}$ \\
Extinction coefficient $(\beta)$ & $1470.5 \mathrm{~m}^{2} / \mathrm{kg}$ \\
Scattering coefficient $(\sigma)$ & $1295.8 \mathrm{~m}^{2} / \mathrm{kg}$ \\
Forward scattering probability $\left(p_{f}\right)$ & 0.110 \\
Backward scattering probability $\left(p_{b}\right)$ & 0.710 \\
Side scattering probability $\left(p_{s}\right)$ & 0.045 \\
\hline
\end{tabular}

The scattering albedo $\omega$, calculated from Equation (10), was 0.88 , and the corrected albedo, $\omega_{\text {corr }}$, was 0.75, which was estimated from Equations (10)-(13).

The optical thickness ( $\tau$ (Equation (14)) in the CPC reactor, estimated for a $\mathrm{TiO}_{2}$ catalyst loading of $0.6 \mathrm{~g} / \mathrm{L}$ and a reactor diameter of $33 \mathrm{~mm}$, was equal to 29.0 , whereas the apparent maximum optical thickness $\tau_{a p p, \max }$ from Equation (15), at this catalyst concentration, was equal to 17.1. The volumetric rate of photon absorption per unit length of the solar CPC reactor $(V R P A / H)$ could then be estimated using the modeling results of the CPC solar reactor previously reported [37], shown in Figure 6. These results were calculated for the solar irradiation conditions of Cali (Colombia), which, however, were very similar to the prevalent irradiation conditions of this study (latitude $3.5^{\circ}$ ). At $\tau_{a p p, \max }=17.1$, the $V R P A / H$ for $\omega=0.88$ equals $0.405 \mathrm{~W} / \mathrm{m}$. Since the total length of the CPC reactor used in the experiments was $12 \mathrm{~m}$, the corresponding $V R P A$ was $4.86 \mathrm{~W}$. Combining Equations (3) and (4) and inverting yields Equation (19),

$$
\frac{1}{\left(-\mathrm{V}_{T} \frac{d[T O C]}{d t_{30 W}}\right)}=\frac{1}{K_{R} k_{T}(V R P A)^{0.5}}\left(\frac{1}{[T O C]}\right)+\frac{1}{k_{T}(V R P A)^{0.5}}
$$

and the kinetic parameters $k_{T}$ and $K_{R}$ were calculated by performing a linear fitting of the experimental data, with the TOC removal rates determined at time zero (Figure 7). The dimensionless parameter $m$ in Equation (4) is related to the probability of electron-hole recombination and can take values within the 
0.5-1.0 range, however, when the UV irradiance is significant and is not the limiting step of the photocatalytic reaction, $m$ can be fixed as 0.5 [38].

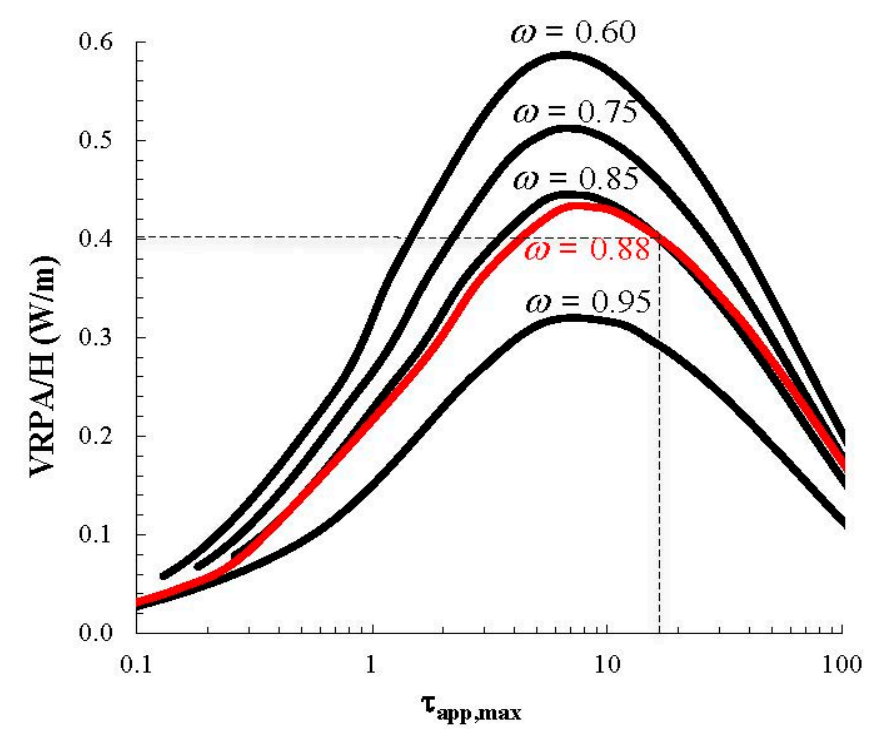

Figure 6. Effect of the maximum optical thickness on the VRPA per unit of length of a CPC solar reactor. Adapted from Colina-Marquez et al. [37].

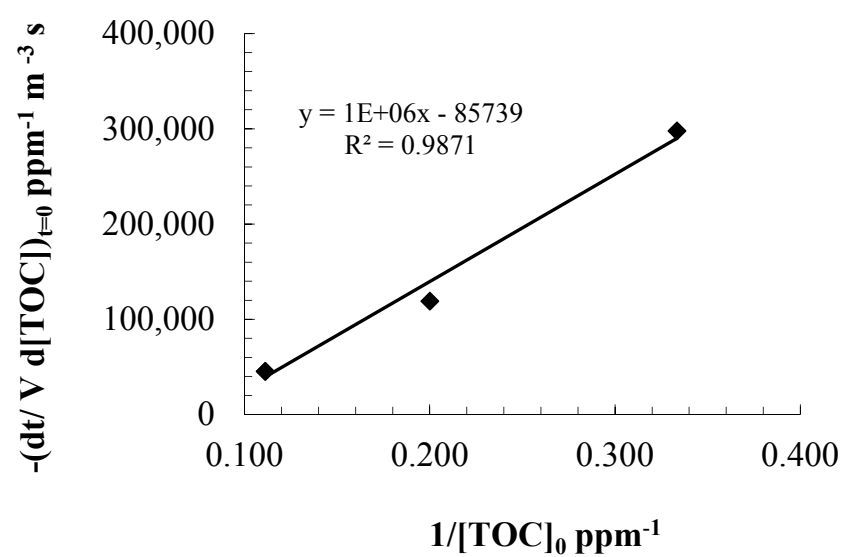

Figure 7. Linear regression for fitting parameters of the kinetic model.

From the slope and the intercept with the vertical axis (Equations (20) and (21)), the reaction kinetics and adsorption constants were estimated:

$$
\begin{aligned}
& \text { slope }=\frac{1}{K_{R} k_{T}(V R P A)^{0.5}}=348,947 \\
& \text { intercept }=\frac{1}{k_{T}(V R P A)^{0.5}}=25,773
\end{aligned}
$$

The estimated kinetic constants values were $k_{T}=1.76 \times 10^{-5} \mathrm{ppm} \cdot \mathrm{m}^{1.5} / \mathrm{s} \cdot \mathrm{W}^{0.5}$ and $K_{R}=7.386 \times 10^{-2} \mathrm{ppm}^{-1}$. The adsorption constant $K_{a d s}$ estimated with the modified L-H kinetic model was one order of magnitude greater than the equilibrium adsorption constant $K_{a d s}$, determined from the dark adsorption experiments. This apparent discrepancy results from the modification of the physical and chemical properties of the 
catalyst surface when this is irradiated with UV photons and when electron-hole pairs are generated [39]. When the $\mathrm{TiO}_{2}$ surface is irradiated, there is an electron exchange with the hydroxyl anions with $\mathrm{pH}$ decrease, therefore, the net electric charge of the catalyst surface becomes positive and this effect might favor the physical adsorption of the anionic chemical species from the contaminants in solution. Nonetheless, the adsorption constant $K_{R}$ estimated still suggests a weak adsorption of the contaminants.

The degradation of the commercial estradiol formulation was modeled in terms of TOC removal, using the proposed model and the kinetic parameters determined for the commercial estradiol formulation. Since the experimental pilot-scale CPC reactor was a flow-through reactor with external recirculation, the simulations and the latter validation were carried out considering the concentration changes after multiple passes through the solar photoreactor. The total number of passes in each simulation was estimated with Equation (22):

$$
n_{\text {pass }}=\frac{Q t_{30 W}}{V_{R}}
$$

where $t_{30 \mathrm{~W}}$ corresponds to the total time of the simulations. One hundred small sub-reactors $(j=1$ to 100$)$ of equal length $\left(L_{\mathrm{j}}=L / 100\right)$ were considered to model the flow-through the CPC reactor during each pass, and the calculations were made considering that each sub-reactor behaved as a turbulent flow reactor. Considering the velocity profiles trough the cross-area of the reactor and the rate law (Equation (4)), the mass balance equation was expressed as follows:

$$
Q \frac{d[T O C]_{r, \theta}}{d V_{R}}=-\frac{k_{T} K_{R}[T O C]_{r, \theta}}{\left(1+K_{R}[T O C]_{j}^{i n}\right)}(L V R P A)_{r, \theta}^{m}
$$

where $T O C_{j}^{\text {in }}$ is the feed TOC concentration to each sub-reactor. Since the LVRPA varies in both the radial and the angular directions, the local reaction rate also varies across the cross sectional area of the tube. The TOC concentration in the reactor further changes along the $z$-axis, therefore, the initial condition was set as follows:

$$
z=0, T O C_{j=1}^{i n}=T O C_{i+1}^{i n}
$$

where $[T O C]_{i+1}^{i n}$ is the TOC concentration from the overall mass balance after each pass (Equation (5)). Obviously, for the first pass $[T O C]_{i=1}^{i n}$ equals the initial TOC concentration in the reactor feed stream.

The local TOC concentration at the exit cross section of each sub-reactor was estimated for each point of the polar grid by solving the differential equation (Equation (23)):

$$
[T O C]_{r, \theta}^{\text {out }}=\exp \left[\ln \left([T O C]_{j}^{\text {in }}\right)-\frac{k_{R} k_{T}}{v_{Z}\left(1+K_{R}[T O C]_{j}^{i n}\right)} \int_{0}^{L_{j}}(L V R P A)_{r, \theta}^{m} d z\right]
$$

where $v_{z}$ is the average velocity of the fluid, which is a function of the radial coordinate (Equation (6)). The average TOC concentration at the exit of each sub-reactor was calculated by integrating the TOC concentration profile along the radial and angular directions taking into account the liquid flow rate:

$$
[T O C]_{j}^{\text {out }}=\frac{\int_{0}^{2 \pi} \int_{0}^{R} r v_{z}[T O C]_{r, \theta}^{\text {out }} d r d \theta}{Q}
$$

which is equivalent to mixing the fluid at the exit of each sub-reactor. 
Finally, Equations (25) and (26) are solved iteratively for each sub-reactor after setting the initial condition:

$$
[T O C]_{j+1}^{i n}=[T O C]_{j}^{o u t}
$$

until the reactor exit at $\mathrm{z}=L$ is reached $(j=100)$.

The reactor analysis presented above neglects the axial mixing of the fluid. Under turbulent flow conditions, it was necessary to assume complete radial and angular mixing, resembling the behavior of a continuous-stirred tank reactor (CSTR) across each cross section.

The calculation of the TOC concentration was made for each pass through the reactor until the number of passes established in Equation (22) was completed ( $i=1$ to $n_{\text {pass }}$ ).

The solid lines illustrated in Figure 8 correspond to the data generated by the model with the kinetic parameters $k_{T}$ and $K_{R}$ determined. The model described the experimental data satisfactorily, although it slightly overestimated the concentration profile at $t_{30 \mathrm{~W}}>15 \mathrm{~min}$, when the initial TOC concentration was $213.6 \mathrm{ppm}$. At lower TOC concentration, the catalyst surface may not be fully saturated with the substrates, and as a result a higher fraction of water adsorption yielded a higher rate of hydroxyl radical generation, ultimately contributing to a higher overall removal of the substrate. Whereas for the higher concentrations, the observed behavior could resemble to zero-order kinetics, for lower concentrations this behavior was closer to a first-order kinetics.

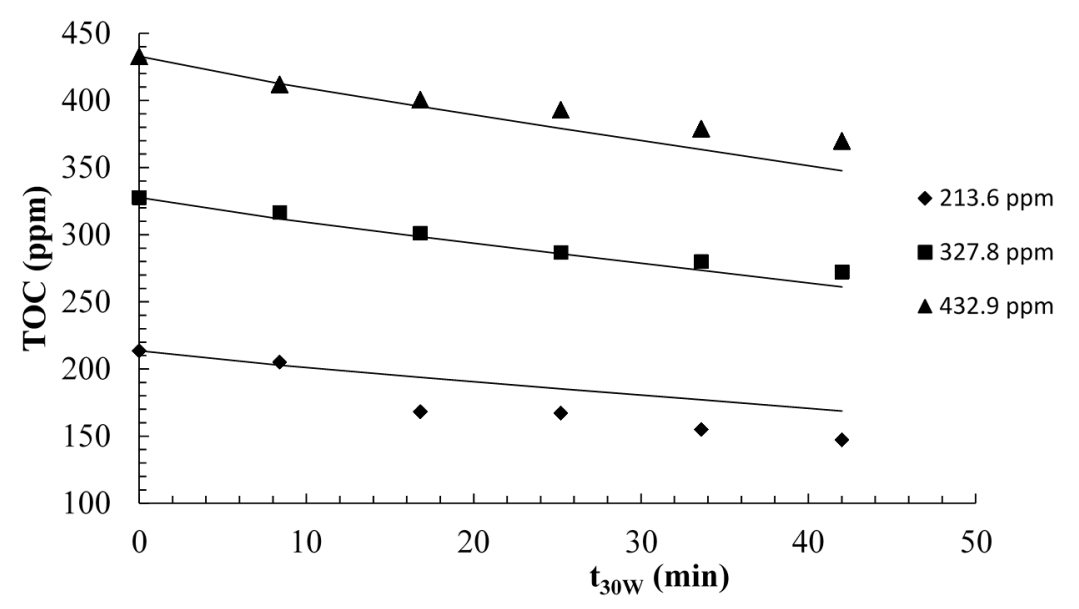

Figure 8. Modeling of the photocatalytic mineralization of commercial estradiol. The initial $\mathrm{pH}$ was 4.6 and the catalyst loading was $0.6 \mathrm{~g} / \mathrm{L}$.

The photoreactor model was further validated by comparing the experimental and model results of the the mineralization of the commercial estradiol formulation, using a different catalyst loading $(0.4 \mathrm{~g} / \mathrm{L})$ and four initial TOC concentrations. The value of the $V R P A / H$ for the model simulations was determined from Figure 6, using the new value of the apparent maximum optical thickness $\left(\tau_{\text {app,max }}\right)$, since this parameter is a function of the catalyst loading. Using Equation (15) $\tau_{a p p, \max }$ was equal to 11.43 , and the VRPA was $5.18 \mathrm{~W}$, which is slightly greater than the value corresponding to the catalyst loading of $0.6 \mathrm{~g} / \mathrm{L}$. In consequence, a greater TOC removal using $0.4 \mathrm{~g} / \mathrm{L}$ of catalyst was expected, since the new $\tau_{\text {app,max }}$ approaches the optimum value (Figure 6). The results shown in Figure 9 demonstrate that the model described the photocatalytic degradation of estrogens satisfactorily, for both 387.7 and $409.5 \mathrm{ppm}$ of TOC as initial concentrations. 


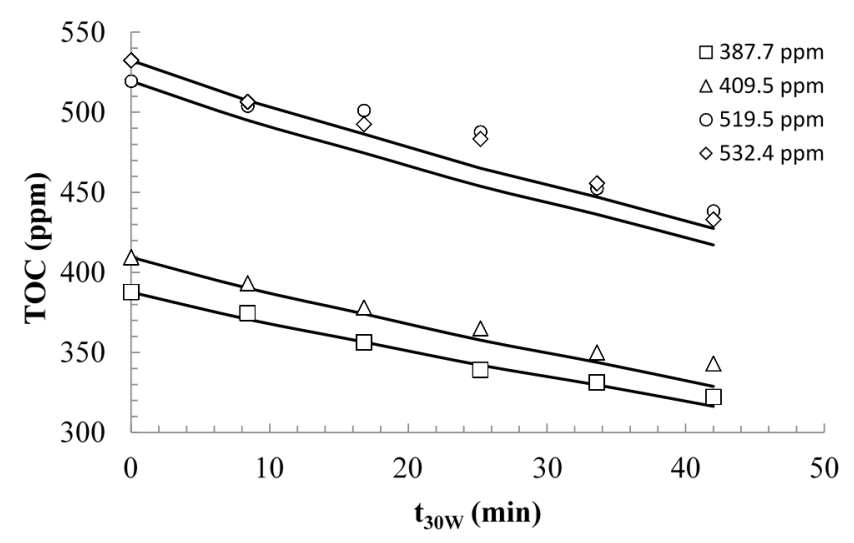

Figure 9. Validation of the TOC photocatalytic degradation with $0.4 \mathrm{~g} / \mathrm{L}$ of catalyst load.

The model appeared to underestimate the experimental results at higher TOC concentrations. One explanation for this behavior is that the underlying assumption of monolayer adsorption described by the $\mathrm{L}-\mathrm{H}$ modeling approach may begin to fail, and that at these high TOC concentrations, the adsorption phenomena may be of multilayer nature, with complete saturation of the catalyst surface. The results shown in Figure 4 also suggest that a multilayer coverage of the catalyst at TOC concentrations higher than $400 \mathrm{ppm}$ may be approached. Both cases lead to a decrease of the rate of $\bullet \mathrm{OH}$ radical generation due to a higher fractional coverage of the surface with estradiols and, in consequence, to a reduction of the rate of TOC mineralization.

Figure 10 shows the fitting of the TOC values predicted by the model with the experimental data obtained in the validation tests. The $\mathrm{R}^{2}$ value points to a satisfactory fitting in general, with low dispersion of the data. As shown in Figure 10, the deviation becomes more significant at higher concentrations of TOC, depicting the possible multilayer adsorption of substrates.



Figure 10. Comparison of the TOC values obtained by the model and the experimental TOC data.

The effect of the catalyst loading is evidenced by the increase of the TOC removal, which was slightly greater with $0.4 \mathrm{~g} / \mathrm{L}$ in comparison to the results with $0.6 \mathrm{~g} / \mathrm{L}(21.6 \% v s .19 .7 \%$, respectively, for the case of $400 \mathrm{ppm}$ of initial TOC concentration). Our previous study [37] established an optimal catalyst loading of $0.33 \mathrm{~g} / \mathrm{L}$ for the $\mathrm{CPC}$ reactor under the same operating conditions and optical parameters used in this study. With a catalyst loading of $0.4 \mathrm{~g} / \mathrm{L}$, which is closer to this optimum, the model predicted a higher rate of contaminant mineralization than with $0.6 \mathrm{~g} / \mathrm{L}$, as predicted by the greater value of the 
$V R P A$. The existence of an optimum in the volumetric rate of photon absorption per unit reactor length $(V R P A / H)$ is explained by a lower rate of photon adsorption at low catalyst concentrations when the catalyst surface area is insufficient for the absorption of the incident photons, and by a high scattering and "clouding" effects at catalyst concentrations much higher than the optimum, since under this situation the absorption of radiation is effective in a cross sectional area which is smaller than the actual physical cross section of the tube.

\section{Experimental Section}

\subsection{Materials and Methods}

The commercial contraceptive pill selected for this study contained $1.5 \mathrm{mg}$ of $17-\beta$ estradiol (E2, as hemihydrate), $2.5 \mathrm{mg}$ of nomegestrol acetate and excipients compounds (lactose monohydrate, microcrystalline cellulose, magnesium stearate and polyvinyl alcohol of unknown concentration) in each caplet. To prepare the estradiol aqueous solution, the caplets were pulverized and $30 \mathrm{~mL}$ of ethanol $\left(\right.$ Merck $^{\circledR}$ ) was added to the powdered caplets to extract the estrogens from the powder. The solution was filtered and the extract was lately dissolved in $40 \mathrm{~L}$ of tap water to perform the solar experimental tests. The concentration of the estradiols in each experiment was adjusted based on the content of multiple caplets. $\mathrm{TiO}_{2}$ Aeroxide ${ }^{\circledR}$ P-25 (Evonik, primary particle size, 20-30 nm by TEM; specific surface area $52 \mathrm{~m}^{2} \cdot \mathrm{g}^{-1}$ by BET; composition $78 \%$ anatase and $22 \%$ rutile by X-ray diffraction) was used in the experiments. The catalyst was added in the reactor and circulated under dark conditions overnight before exposing the reactor to sunlight the next day. Sampled collected from the reactor containing $\mathrm{TiO}_{2}$ were immediately filtered through a $0.45 \mu \mathrm{m}$ Nylon filter (Millipore, Billerica, MA, USA) prior to immediate further quantitative analysis. The residual concentration of estrogens in the water was determined by UV-spectroscopy (Shimadzu UV1800 spectrophotometer) by measuring the absorbance in the UV region. The calibration curve and the absorbance spectra of estrogens are shown in Figure 11. The total organic carbon (TOC) of the samples was measured using a Shimadzu TOC-VCPH.

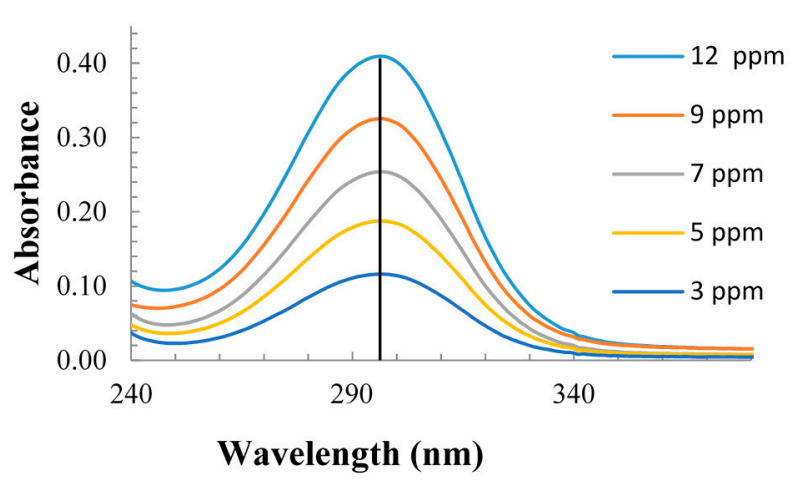

(a)

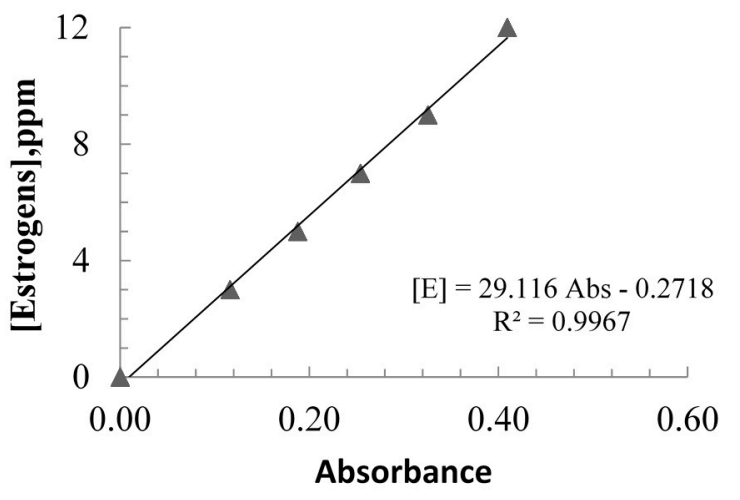

(b)

Figure 11. (a) UV absorbance of estrogens at different concentrations, showing a peak absorption wavelength at $297 \mathrm{~nm}$. (b) Calibration curve for estrogens in tap water.

The adsorption tests were performed in sealed $500 \mathrm{~mL}$-beakers containing $300 \mathrm{~mL}$ of an aqueous solutions of estrogens and suspended $\mathrm{TiO}_{2}$ Aeroxide ${ }^{\circledR} \mathrm{P}-25$ at known concentrations. The samples were 
kept in a chamber under dark conditions and continuous magnetic stirring for $12 \mathrm{~h}$. The concentration of estrogens in the water prior to adding the catalyst and after reaching equilibrium in the presence of catalyst was measured by UV-spectroscopy and TOC analysis.

The incident solar UV radiation accumulated in the photoreactor was measured by a UV radiometer (Delta OHM 210.2) with an UV-B probe, which covers the wavelength range between 280 and $315 \mathrm{~nm}$. The effect of UV-A radiation from the solar radiation spectrum up to the absorption band edge of $\mathrm{TiO}_{2}$ (384 nm) was evaluated with a common extrapolation by considering that the UV-B is approximately the $10 \%$ of the UV A+B radiation. The dissolved oxygen concentration in the water was monitored with a Spectroquant Pharo 3000. To account for variation in solar irradiance during the day, the photocatalytic treatment time was standardized based on the $t_{30 \mathrm{w}}$ time, which considers that the average UV photon irradiance during a clear sunny day is $30 \mathrm{~W} / \mathrm{m}^{2}$ [36].

\subsection{Photocatalytic Reactor}

The photolytic and photocatalytic tests were performed in a solar CPC photoreactor shown in Figure 12. It consisted of ten Duran ${ }^{\circledR}$ glass tubes (1200 mm in length, $32 \mathrm{~mm} \mathrm{OD,} 1.4 \mathrm{~mm}$ wall thickness), supported by a metal structure. The reactor was operated in a recirculation mode using a $40 \mathrm{~L}$ recycle feed tank, a recycling centrifugal pump ( $1 / 2 \mathrm{hp}$ of nominal power) that delivered $30.2 \mathrm{~L} / \mathrm{min}$. The Reynolds number in the CPC for these operating conditions was 19,400 , therefore the flow regime was fully developed and turbulent. The flow rate was measured by a calibrated flow meter. The pipeline and accessories used in the pilot plant were made of PVC, 1-inch diameter.

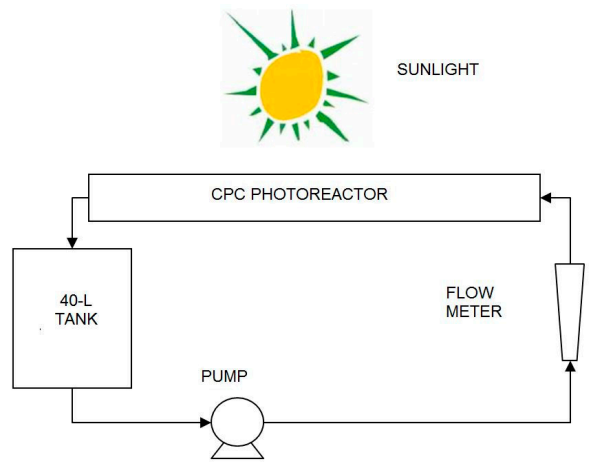

(a)

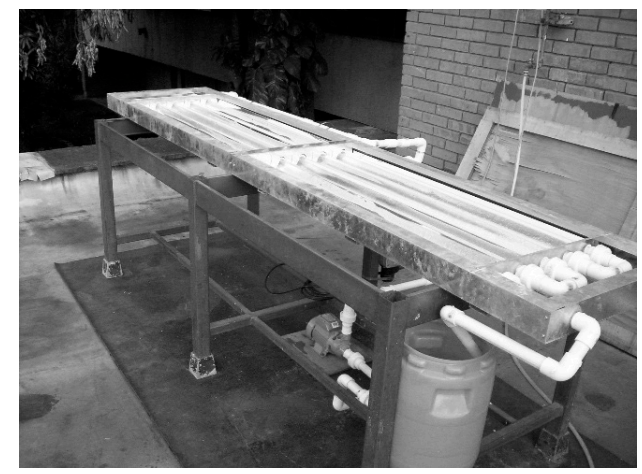

(b)

Figure 12. Pilot-scale solar CPC: (a) scheme of experimental setup and (b) photocatalytic reactor (Universidad del Valle, Cali-Colombia).

The geometry of the CPC is described in Figure 13. The curvature of the CPC involute (Figure 13) is described mathematically by the equations:

$$
\begin{gathered}
\rho=r \theta \text { for }|\theta| \leq \theta_{a}+\pi / 2 \quad \text { part } \mathrm{AB} \text { of the curve } \\
\rho=r \frac{\theta+\theta_{a}+\pi / 2-\cos \left(\theta-\theta_{a}\right)}{1-\sin \left(\theta-\theta_{a}\right)} \text { for } \theta_{a}+\pi / 2 \leq|\theta| \leq \frac{3 \pi}{2}-\theta_{a} \text { part BC of the curve }
\end{gathered}
$$

where $\rho$ is the radial coordinate of the involute, $r$ is the reactor radius, $\theta$ is the angular coordinate of the involute and $\theta_{a}$ is the acceptance angle of the collector. For this case, the chosen acceptance angle was $90^{\circ}$. 


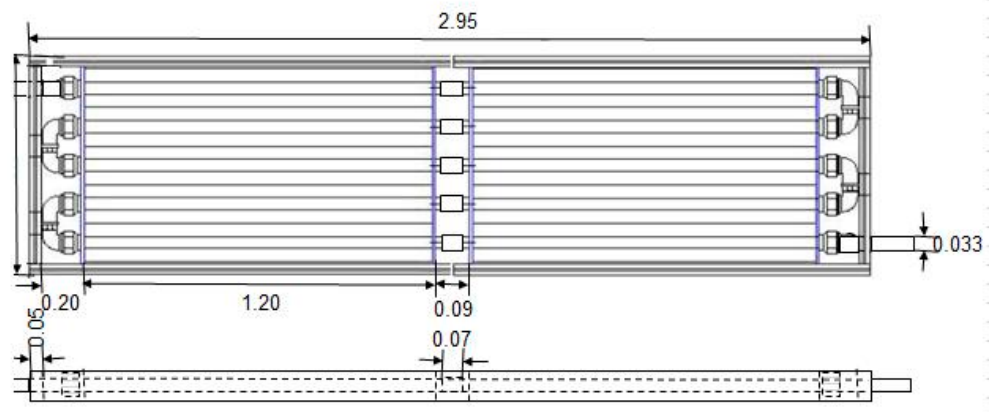

(a)

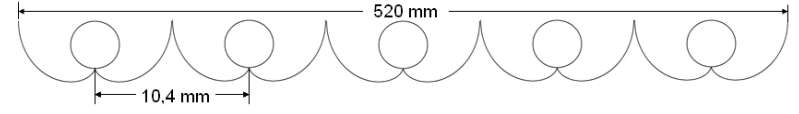

(b)

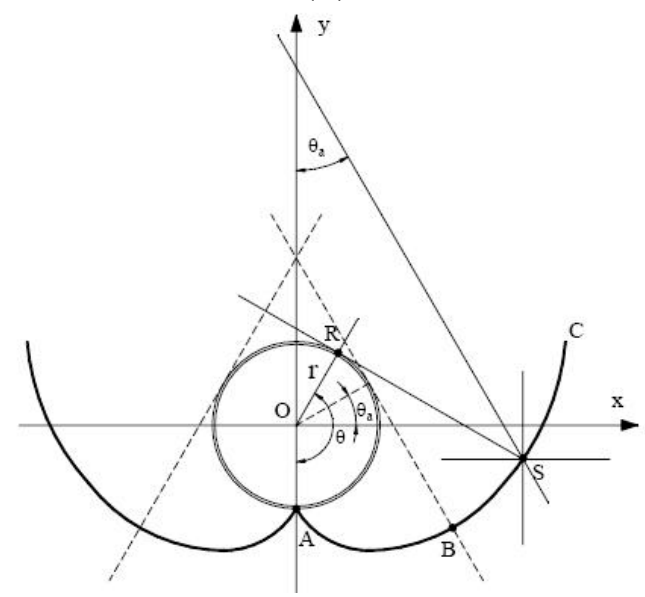

(c)

Figure 13. Solar CPC Photoreactor details: (a) superior and lateral views and (b) frontal view showing the curvature of the compound parabolic collectors; (c) CPC involute design.

\section{Conclusions}

The modified Langmuir-Hinshelwood $(\mathrm{L}-\mathrm{H})$ rate model, including the effect of photon adsorption and scattering represented by the SFM, modeled satisfactorily the removal of the total organic carbon of commercial estradiols (17- $\beta$ estradiol and nomegestrol acetate) aqueous solutions, in a solar CPC photoreactor with relative errors of 5\%. The application of solar photolysis without catalyst demonstrated a low rate of mineralization, although the rate of estrogens degradation was faster. The effect of solar photolysis could be neglected in the modeling of the TOC removal and the modified $\mathrm{L}-\mathrm{H}$ rate model accounting for photocatalysis allowed the estimation of the kinetic parameters (reaction kinetics and adsorption constants) independent of the radiant field in the CPC photoreactor. It is important to note that the adsorption constant estimated with the Langmuir isotherm model under dark conditions, was one-order of magnitude greater than the adsorption constant obtained from the modified L-H kinetic model during the photocatalytic experiments. This demonstrates that the adsorption of estrogens over the $\mathrm{TiO}_{2}$ catalyst surface is significantly affected under photon irradiation, as a result of the oxidation of the adsorbed estrogens. It was also demonstrated that at catalyst concentrations closer to the optimum predicted from radiation modeling consideration, the rate of TOC removal increased, and that the model 
could follow these trends. This study highlights the importance of kinetics and reactor modeling, which should always include the effect of the radiation field as a fundamental step, since without photon absorption there cannot be photocatalysis, as well as without reactants, there cannot be reactions. The current literature too often neglects this aspect in kinetic modeling.

\section{Acknowledgments}

Colina-Marquez and Machuca-Martinez thank Colciencias grant No. 117-521-28546 for the financial support and the chemical engineers Jaime Gomez and Leandro Quevedo for gathering the experimental data and running the simulations. Colina-Marquez also thanks the British Council for awarding the Travel Grant for Researcher Links, which made the collaboration between the research groups from Colombia and the United Kingdom possible.

\section{Author Contributions}

J.C.M., F.M.M. and G.L.P. wrote the paper and modeled the CPC photoreactor. In addition, J.C.M. developed the pilot-scale photoreactor, performed the experiments and analyzed the results.

\section{Conflicts of Interest}

The authors declare no conflict of interest.

\section{Nomenclature}

$\begin{array}{ll}a & \text { SFM parameter, dimensionless } \\ b & \text { SFM parameter, dimensionless } \\ f & \text { friction factor, dimensionless } \\ I & \mathrm{UV} \text { radiation intensity, } \mathrm{W} \cdot \mathrm{m}^{-2} \\ k_{T} & \text { kinetic constant, } \mathrm{mol} \cdot \mathrm{L}^{-1} \cdot \mathrm{s}^{-1} \cdot \mathrm{W}^{-0.5} \cdot \mathrm{m}^{1.5} \\ K_{a d s} & \text { adsorption equilibrium } \mathrm{constant}, \mathrm{L} \cdot \mathrm{mol}^{-1} \\ K_{R} & \text { reaction binding constant, } \mathrm{L} \cdot \mathrm{mol}^{-1} \\ L & \text { reactor length, } \mathrm{m} \\ L V R P A & \text { local volumetric rate of photon absorption, } \mathrm{W} \cdot \mathrm{m}^{-3} \\ m & \text { reaction order respect to the } \mathrm{LVRPA}, \text { dimensionless } \\ n & \text { parameter of velocity profile for turbulent regime, dimensionless } \\ n_{p a s s} & \text { number of pass of the fluid through the reactor space, dimensionless } \\ p_{b} & \text { probability of backward scattering, dimensionless } \\ p_{f} & \text { probability of forward scattering, dimensionless } \\ p_{s} & \text { probability of side scattering, dimensionless } \\ Q & \text { flow rate, } \mathrm{m}^{3} \cdot \mathrm{s}{ }^{-1} \\ r & \text { radial coordinate, } \mathrm{m} \\ r_{p} & \text { auxiliary coordinate in the photon flux direction, } \mathrm{m} \\ R & \text { reactor radius, } \mathrm{m} \\ t & \text { time, } \mathrm{s}\end{array}$




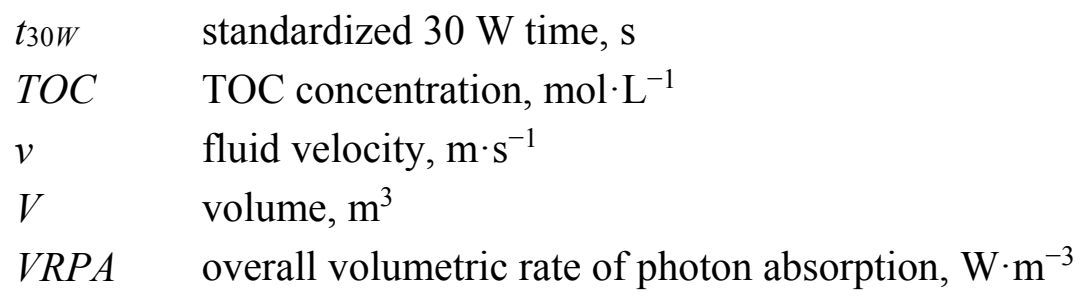

Greek Letters

$\delta$

$\gamma$

$\kappa$

$\lambda$

$\theta$

$\sigma$

$\tau$

$\varpi$

$\omega$

Subscripts

$\begin{array}{ll}\text { app } & \text { apparent } \\ \text { average } & \text { average } \\ \text { corr } & \text { corrected } \\ \max & \text { maximum } \\ \text { min } & \text { minimum } \\ r & \text { radial coordinate } \\ R & \text { reactor } \\ \text { total } & \text { total radiation } \\ T & \text { total } \\ z & \text { axial coordinate } \\ 0 & \text { relative to incident radiation, or initial condition } \\ \lambda & \text { radiation wavelength } \\ \theta & \text { angular coordinate } \\ \omega c \text { corr } & \text { corrected albedo }\end{array}$

reactor thickness, $\mathrm{m}$

SFM parameter, dimensionless

specific mass absorption coefficient, $\mathrm{m}^{2} \cdot \mathrm{kg}^{-1}$

radiation wavelength, $\mathrm{nm}$

polar coordinate, radians

specific mass scattering coefficient, $\mathrm{m}^{2} \cdot \mathrm{kg}^{-1}$

optical thickness, dimensionless

declination angle, radians

scattering albedo, dimensionless

Superscripts
in
reactor inlet
out

\section{References}

1. Thomaidi, V.S.; Stasinakis, A.S.; Borova, V.L.; Thomaidis, N.S. Is there a risk for the aquatic environment due to the existence of emerging organic contaminants in treated domestic wastewater? Greece as a case-study. J. Hazard. Mater. 2015, 283, 740-747. 
2. Ramirez, A.J.; Brain, R.A.; Usenko, M.A.; Mottaleb, M.A.; O’Donnell, J.G.; Stahl, L.L.; Wathen, J.B.; Snyder, B.D.; Pitt, J.L.; Perez-Hurtado, P.; et al. Occurrence of pharmaceuticals and personal care products in fish: Results of a national pilot study in the United States. Environ. Toxicol. Chem. 2009, 28, 2587-2597.

3. Loos, R.; Gawlik, B.M.; Locoro, G.; Rimaviciute, E.; Contini, S.; Bidoglio, G. EU-wide survey of polar organic persistent pollutants in European river waters. Environ. Pollut. 2009, 157, 561-568.

4. Yang, Y.; Fu, J.; Peng, H.; Hou, L.; Liu, M.; Zhou, J.L. Occurrence and phase distribution of selected pharmaceuticals in the Yangtze Estuary and its coastal zone. J. Hazard. Mater. 2011, 190, 588-596.

5. Lindberg, R.H.; Östman, M.; Olofsson, U.; Grabic, R.; Fick, J. Occurrence and behaviour of 105 active pharmaceutical ingredients in sewage waters of a municipal sewer collection system. Water Res. 2014, 58, 221-229.

6. Bu, Q.; Wang, B.; Huang, J.; Deng, S.; Yu, G. Pharmaceuticals and personal care products in the aquatic environment in China: A review. J. Hazard. Mater. 2013, 262, 189-211.

7. Liu, Z.H.; Ogejo, J.A.; Pruden, A.; Knowlton, K.F. Occurrence, fate and removal of synthetic oral contraceptives (SOCs) in the natural environment: A review. Sci. Total. Environ. 2011, 409, 5149-5161.

8. Landrigan, P.; Garg, A.; Droller, D.B.J. Assessing the effects of endocrine disruptors in the National Children's Study. Environ. Health Perspect. 2003, 111, 1678-1682.

9. Colborn, T.; Vom Saal, F.S.; Soto, A.M. Developmental effects of endocrine-disrupting chemicals in wildlife and humans. Environ. Health Perspect. 1993, 101, 378-384.

10. Corcoran, J.; Winter, M.J.; Tyler, C.R. Pharmaceuticals in the aquatic environment: A critical review of the evidence for health effects in fish. Environ. Health Perspect. 2010, 40, 287-304.

11. Kidd, K.A.; Blanchfield, P.J.; Mills, K.H.; Palace, V.P.; Evans, R.E.; Lazorchak, J.M.; Flick, R.W. Collapse of a fish population after exposure to a synthetic estrogen. PNAS 2007, 104, 8897-8901.

12. Yang, L.P.H.; Plosker, G.L. Nomegestrol acetate/estradiol: In oral contraception. Drugs 2012, 72, 1917-1928.

13. Fernández, M.; Fernández, M.; Laca, A.; Laca, A.; Díaz, M. Seasonal occurrence and removal of pharmaceutical products in municipal wastewaters. J. Environ. Chem. Eng. 2014, 2, 495-502.

14. Collado, N.; Rodriguez-Mozaz, S.; Gros, M.; Rubirola, A.; Barceló, D.; Comas, J.; Rodriguez-Roda, I.; Buttiglieri, G. Pharmaceuticals occurrence in a WWTP with significant industrial contribution and its input into the river system. Environ. Pollut. 2014, 185, 202-212.

15. Prieto-Rodriguez, L.; Miralles-Cuevas, S.; Oller, I.; Agüera, A.; Puma, G.L.; Malato, S. Treatment of emerging contaminants in wastewater treatment plants (WWTP) effluents by solar photocatalysis using low $\mathrm{TiO}_{2}$ concentrations. J. Hazard. Mater. 2012, 211-212, 131-137.

16. Kanakaraju, D.; Glass, B.D.; Oelgemöller, M. Titanium dioxide photocatalysis for pharmaceutical wastewater treatment. Environ. Chem. Lett. 2014, 12, $27-47$.

17. Choi, J.; Lee, H.; Choi, Y.; Kim, S.; Lee, S.; Lee, S.; Choi, W.; Lee, J. Heterogeneous photocatalytic treatment of pharmaceutical micropollutants: Effects of wastewater effluent matrix and catalyst modifications. Appl. Catal. B Environ. 2014, 147, 8-16. 
18. Yang, H.; An, T.; Li, G.; Song, W.; Cooper, W.J.; Luo, H.; Guo, X. Photocatalytic degradation kinetics and mechanism of environmental pharmaceuticals in aqueous suspension of $\mathrm{TiO}_{2}$ : A case of $\beta$-blockers. J. Hazard. Mater. 2010, 179, 834-839.

19. Mboula, V.M.; Héquet, V.; Andrès, Y.; Gru, Y.; Colin, R.; Doña-Rodríguez, J.M.; Silva, A.M.T.; Pastrana-Martínez, L.M.; Leleu, M.; Tindall, A.J.; et al. Photocatalytic degradation of estradiol under simulated solar light and assessment of estrogenic activity. J. Hazard. Mater. 2010, 179, 834-839.

20. Koutantou, V.; Kostadima, M.; Chatzisymeon, E.; Frontistis, Z.; Binas, V.; Venieri, D.; Mantzavinos, D. Solar photocatalytic decomposition of estrogens over immobilized zinc oxide. Catal. Today 2013, 209, 66-73.

21. Frontistis, Z.; Fatta-Kassinos, D.; Mantzavinos, D.; Xekoukoulotakis, N.P. Photocatalytic degradation of $17 \alpha$-ethynylestradiol in environmental samples by $\mathrm{ZnO}$ under simulated solar radiation. J. Chem. Technol. Biotechnol. 2012, 87, 1051-1058.

22. Zhang, W.; Li, Y.; Su, Y.; Mao, K.; Wang, Q. Effect of water composition on $\mathrm{TiO}_{2}$ photocatalytic removal of endocrine disrupting compounds (EDCs) and estrogenic activity from secondary effluent. J. Hazard. Mater. 2012, 215-216, 252-258.

23. Li Puma, G.; Puddu, V.; Tsang, H.K.; Gora, A.; Toepfer, B. Photocatalytic oxidation of multicomponent mixtures of estrogens (estrone (E1), 17 $\beta$-estradiol (E2), 17 $\alpha$-ethynylestradiol (EE2) and estriol (E3)) under UVA and UVC radiation: Photon absorption, quantum yields and rate constants independent of photon absorption. Appl. Catal. B Environ. 2010, 99, 388-397.

24. Benotti, M.J.; Stanford, B.D.; Wert, E.C.; Snyder, S.A. Evaluation of a photocatalytic reactor membrane pilot system for the removal of pharmaceuticals and endocrine disrupting compounds from water. Water Res. 2009, 43, 1513-1522.

25. Li Puma, G.; Brucato, A. Dimensionless analysis of slurry photocatalytic reactors using two-flux and six-flux radiation absorption-scattering models. Catal. Today 2007, 122, 78-90.

26. Brucato, A.; Cassano, A.E.; Grisafi, F.; Montante, G.; Rizzuti, L.; Vella, G. Estimating radiant fields in flat heterogeneous photoreactors by the six-flux model. AICHE J. 2006, 52, 3882-3890.

27. Li Puma, G.; Gora, A.; Toepfer, B. Photocatalytic oxidation of multicomponent solutions of herbicides: Reaction kinetics analysis with explicit photon absorption effects. Appl. Catal. B Environ. 2006, $68,171-180$.

28. Chowdhury, R.R.; Charpentier, P.A.; Ray, M.B. Photodegradation of $17 \beta$-estradiol in aquatic solution under solar irradiation: Kinetics and influencing water parameters. J. Photochem. Photobiol. A 2011, 219, 67-75.

29. Leech, D.M.; Snyder, M.T.; Wetzel, R.G. Natural organic matter and sunlight accelerate the degradation of 17ß-estradiol in water. Sci. Total Environ. 2009, 407, 2087-2092.

30. Dillert, R.; Cassano, A.; Goslich, R.; Bahnemann, D. Large scale studies in solar catalytic wastewater treatment. Catal. Today 1999, 54, 267-282.

31. Alfano, O.M.; Bahnemann, D.; Cassano, A.E.; Dillert, R.; Goslich, R. Photocatalysis in water environments using artificial and solar light. Catal. Today 2000, 58, 199-230.

32. Konstantinou, K.; Albanis, T. Degradation pathways and intermediates of photocatalytic transformation of major pesticide groups in aqeous $\mathrm{TiO}_{2}$ suspensions using artificial and solar light: A review. Appl. Catal. B Environ. 2003, 42, 319-335. 
33. Méndez-Arriaga, F.; Maldonado, M.; Giménez, J.; Esplugas, S.; Malato, S. Abatement of ibuprofen by solar photocatalysis process: Enhancement and scale up. Catal. Today 2009, 144, 112-116.

34. Minero, C.; Pelizzetti, E.; Malato, S.; Blanco, J. Large solar plant photocatalytic water decontamination: Effect of operational parameters. Sol. Energy 1996, 56, 421-428.

35. Ohko, Y.; Iuchi, K.I.; Niwa, C.; Tatsuma, T.; Nakashima, T.; Iguchi, T.; Kubota, Y.; Fujishima, A. $17 \beta$-estradiol degradation by $\mathrm{TiO}_{2}$ photocatalysis as a means of reducing estrogenic activity Environ. Sci. Technol. 2002, 36, 4175-4181.

36. Colina-Márquez, J.; Machuca-Martínez, F.; Li Puma, G. Photocatalytic mineralization of commercial herbicides in a pilot-scale solar CPC reactor: Photoreactor modeling and reaction kinetics constants independent of radiation field. Environ. Sci. Technol. 2009, 43, 8953-8960.

37. Colina-Márquez, J.; Machuca, F.; Li Puma, G. Radiation Absorption and Optimization of Solar Photocatalytic Reactors for Environmental Applications. Environ. Sci. Technol. 2010, 44, 5112-5120.

38. Turchi, C.S.; Ollis, D.F. Photocatalytic degradation of organic water contaminants: Mechanisms involving hydroxyl radical attack. J. Catal. 1990, 122, 178-192.

39. Valente, J.P.S.; Padilha, P.M.; Florentino, A.O. Studies on the adsorption and kinetics of photodegradation of a model compound for heterogeneous photocatalysis onto $\mathrm{TiO}_{2}$. Chemosphere 2006, 64, 1128-1133.

Sample Availability: Samples of the compounds are not available from the authors.

(C) 2015 by the authors; licensee MDPI, Basel, Switzerland. This article is an open access article distributed under the terms and conditions of the Creative Commons Attribution license (http://creativecommons.org/licenses/by/4.0/). 